\title{
The Study of Seismic Response on Accelerated Contained Fluid
}

\author{
Kamila Kotrasova and Eva Kormanikova \\ Department of Structural Mechanics, Institute of Structural Engineering, The Technical University of Košice, \\ Faculty of Civil Engineering, Vysokoskolska 4, 04200 Košice, Slovakia \\ Correspondence should be addressed to Kamila Kotrasova; kamila.kotrasova@tuke.sk
}

Received 17 October 2016; Revised 30 January 2017; Accepted 5 February 2017; Published 19 March 2017

Academic Editor: Nikos Mastorakis

Copyright ( 92017 Kamila Kotrasova and Eva Kormanikova. This is an open access article distributed under the Creative Commons Attribution License, which permits unrestricted use, distribution, and reproduction in any medium, provided the original work is properly cited.

\begin{abstract}
Ground-supported cylindrical tanks are strategically very important structures used to store a variety of liquids. This paper presents the theoretical background of fluid effect on tank when a fluid container is subjected to horizontal acceleration. Fluid excites the hydrodynamic (impulsive and convective) pressures, impulsive and convective (sloshing) actions. Seismic response of cylindrical fluid filling tanks fixed to rigid foundations was calculated for variation of the tank slenderness parameter. The calculating procedure has been adopted in Eurocode 8.
\end{abstract}

\section{Introduction}

Liquid-containing cylindrical tanks are strategically very important structures used in water distribution systems and in industries for storing water for firefighting, petroleum, oil and liquefied natural gas, chemical, toxic, flammable, and radioactive liquids. These tanks are mainly of two types: ground-supported cylindrical tanks (concrete, prestressed concrete, and steel) and elevated tanks [1-3].

Seismic analysis of liquid-containing tanks requires special consideration and is different from analysis of buildings [4-7]. The fluid inside of tanks exerts hydrodynamic forces on the tank walls and base. The knowledge of liquid hydrodynamic pressures developed during an earthquake is important for design of tanks, because stresses of the tank wall depend on distribution of loading along the wall height. The first solution structure of a problem was by Westergaard (1933), who determined the pressures on a rectangular dam subjected to horizontal acceleration. Hopkins and Rodriquez (1934) gave the first report on analytical and experimental observations of rigid rectangular tanks under a simulated horizontal earthquake excitation. Jacobsen analyzed, in 1949 and 1951, a rigid cylindrical liquid-containing tank and cylindrical pier surrounded by liquid, subjected to horizontal acceleration. Housner (1963) derived the expressions for distribution of hydrodynamic pressure on a rigid tank wall due to lateral base excitation and considered impulsive and convective components of hydrodynamic pressure. Veletsos (1984) obtained also the distribution of hydrodynamic pressure on rigid as well as flexible wall.

Historically, mechanical models were developed for tank with rigid walls. Housner [8] simplified the method of hydrodynamic analysis in system tank-liquid and introduced the concept of two dynamic components: dynamic impulsive and convective masses. Housner established spring-mass system, which simulates the impulsive and convective mode of vibration of tank-fluid system modified by Graham and Rodriquez (1952) and Epstein (1976). Wozniak and Michell (1978) generalized the Housner model for short and slender tanks. Velestos and Yang (1977) used a different approach to arrive at a similar type of mechanical model for circular rigid tanks. Haround and Housner (1981) and Velestos (1984) developed mechanical model for flexible tanks. Malhotra et al. [9] simplified the flexible model of Velestos (1984) and studied the dynamic behavior of unanchored and baseisolated liquid cylindrical storage tanks [10, 11].

The seismic design of circular tanks is recommended by various codes of practices; their implementation strategy is rather varied leading to significantly different design forces in some cases [12]. Of the best structural engineering design codes that tackle fluid tank systems are [12-14] the American Concrete Institute, ACI 350.3, Eurocode 8 [15], the Standards Association of New Zealand, NZS, and Indian code IS 1893-1984 [16]. These codes address ground-supported 


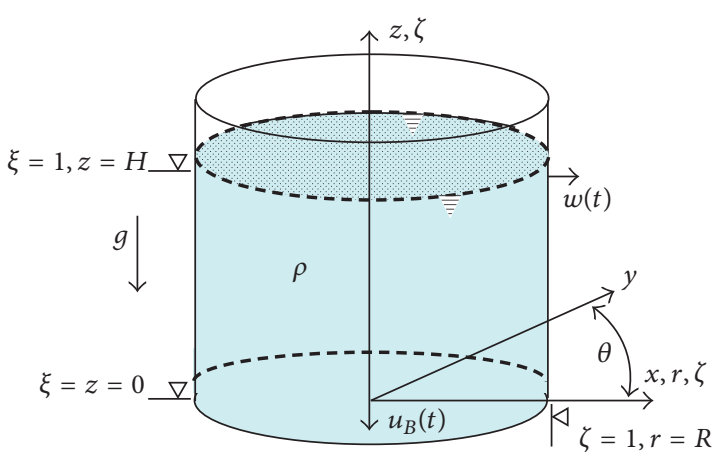

FIGURE 1: Vertical circular tank.

circular and rectangular concrete tanks with fixed or flexible bases.

European Committee for Standardization prepared code Eurocode 8 (2006). Part 4 [15] of this code is related to tanks, silos, and pipelines. Eurocode 8 uses approach of Veletsos (1984) to get hydrodynamic pressure distribution in circular tanks. Eurocode 8 mentions mechanical model of Veletsos and Yang (1977) as an acceptable procedure for rigid circular tanks. Models of Haroun and Housner (1981) and Veletsos (1984) are described along with the procedure of Malhotra et al. (2000) [9] for flexible circular tanks. Model of Housner (1963) is suggested for rigid rectangular tanks.

In regard to the combination procedure of the impulsive forces and the convective forces, Eurocode 8 suggests the absolute sum combination procedure of the impulsive forces and the convective forces, while the ACI, NZS, and IS suggest the Square Root Sum of the Squares method (SRSS) [14, 16, 17].

In this paper, analysis for the seismic design of fluid filling in unanchored rigid vertical circular tanks on-ground, fixed to the foundation, presented by Eurocode 8 is provided $[5,15]$.

\section{Seismic Analysis of Liquid-Filled Tanks}

Under earthquake loading, container walls and liquid are subjected to horizontal acceleration. The seismic load acting on wall and bottom of cylindrical tanks (Figure 1) can be divided into the following components:

(i) The rigid impulsive component, caused by the inertia of the liquid, if the rigid tank moves together with the foundation

(ii) The convective load component, the fluid vibration in the rigid tank (sloshing)

(iii) The impulsive flexible tank shell (e.g., steel tanks) with the liquid [12].

The motion of contained fluid in unanchored rigid vertical circular tanks on-ground, fixed to the foundation tank, may by expressed as the sum of two separate contributions, called "rigid impulsive" and "convective," respectively. The "rigid impulsive" component satisfies exactly the boundary conditions at the walls and the bottom of the tank but, incorrectly, due to the presence of the waves in the dynamic response, gives zero pressure at the original position of the free surface of the fluid. The second "convective" term does not alter those boundary conditions that are already satisfied, while fulfilling the correct equilibrium condition at the free surface. Use is made of a cylindrical coordinate system, $r, z$, $\theta$, with origin at the center of the tank bottom, with $z$ vertical axis; $R$ is the radius of fluid filling; and $H$ is the original height of the free surface of fluid; see Figure 1. The mass density of the fluid is $\rho, \xi=r / R$ is nondimensional radius, and $\zeta=z / H$ is dimensionless coordinate [15].

2.1. Rigid Impulsive Component. The seismic loads acting on wall and bottom of cylindrical tanks (Figure 1) can be divided into the following components.

The spatial-temporal variation of the "rigid impulsive" pressure is given by the expression

$$
p_{i}(\xi, \zeta, \theta, t)=C_{i}(\xi, \zeta) \rho H \cos \theta A_{g}(t)
$$

where

$$
C_{i}(\xi, \zeta)=2 \sum_{n=0}^{\infty} \frac{(-1)^{n}}{I_{1}^{\prime}\left(\nu_{n} / \gamma\right) \nu_{n}^{2}} \cos \left(\nu_{n} \zeta\right) I_{1}\left(\frac{\nu_{n}}{\gamma} \xi\right)
$$

$\nu_{n}=\pi(2 n+1) / 2$ and $\gamma=H / R, I_{1}(\cdot)$ is the modified Bessel function of order 1 , and $I_{1}^{\prime}(\cdot)$ is derivate that can be expressed in terms of modified Bessel function of orders 0 and $1 I_{1}^{\prime}(x)=d I_{1}(x) / d x=I_{0}(x)-I_{1}(x) / x$. The function $C_{i}$ gives the distribution along the height of the timedependence pressure $p_{i}$. $\theta$ is angle of circumference, $\gamma=H / R$ is slenderness parameter, and $A_{g}(t)$ is the free-field ground horizontal acceleration of ground with peak value denoted by $a_{g}$. The result of an equivalent single-degree-of-freedom system is $m_{i}$ with the impulsive period $T_{i}$. The distribution $p_{i}$ along the height of tank wall gives the function $C_{i}$ (see (2)) for $\xi=1$ (i.e., at the wall of the tank) and $\cos \theta=1$ (i.e., in the plane of the horizontal seismic action). Figure 2 presents the vertical distribution of impulsive pressure $p_{i}$ on the tank wall along the wall height, normalized to $\rho R a_{g}$, for seven values of the slenderness parameter $\gamma=H / R$.

For a number of purposes it is useful to evaluate the horizontal resultant of the pressure at the base of the wall, the total base shear, and the moments of the pressures with respect to an axis orthogonal to the direction of the seismic motion. $M_{i}$ is the total impulsive (bending) moment, with respect to an axis orthogonal to the direction of the seismic action motion, immediately above the tank bottom and includes only the contributions of the pressures on the walls (see (7)). $M_{i}^{*}$ is the total impulsive (overturning) moment immediately below the tank bottom and includes the contributions of the pressures on the walls and of those on the bottom (see (5)).

The horizontal impulsive pressure resultant, total impulsive base shear, at the base of the wall is

$$
Q_{i}(t)=m_{i} A_{g}(t),
$$




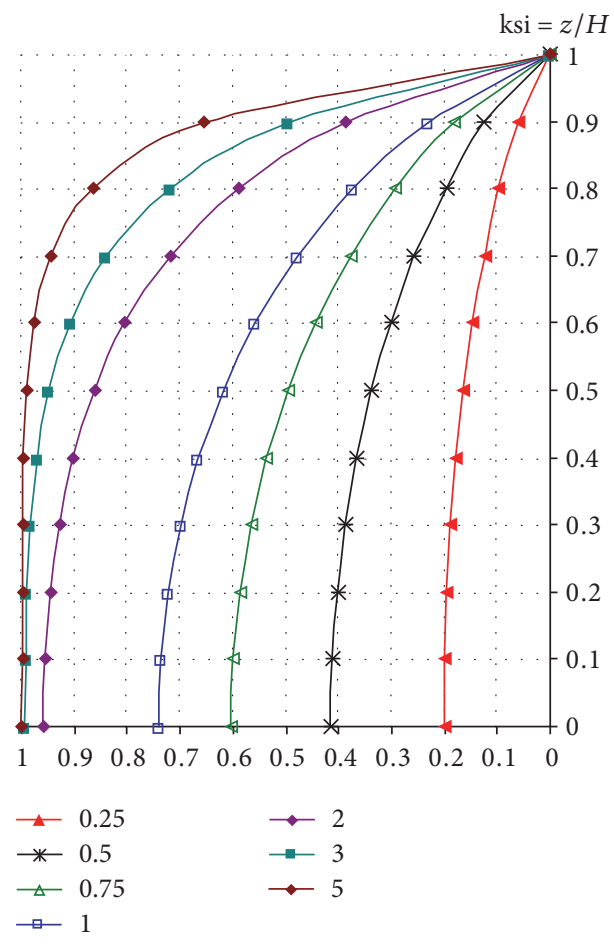

FIGURE 2: Variation of vertical distribution function of the impulsive pressure along the wall height for seven values of the tank slenderness parameter $\gamma=H / R$, normalized to $\rho R a_{g}$.

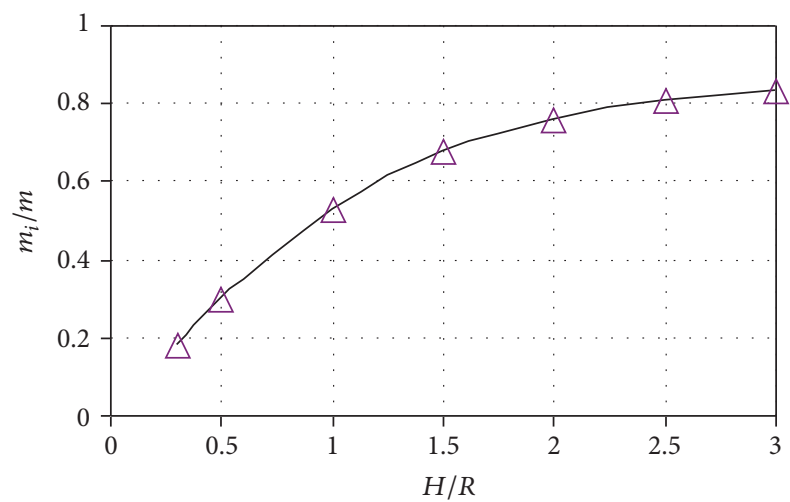

Figure 3: Ratios $m_{i} / m$ as function of the tank slenderness parameter.

where $m_{i}$ is called impulsive mass and indicates the mass of the contained fluid moved together with the walls and $m_{i}$ is given by the expression

$$
m_{i}=m 2 \gamma \sum_{n=0}^{\infty} \frac{I_{1}\left(v_{n} / \gamma\right)}{v_{n}^{3} I_{1}^{\prime}\left(v_{n} / \gamma\right)},
$$

where $m=\rho \pi R^{2} H$ is total mass of the fluid contained in tank.

The quantities $m_{i}$ are plotted in Figure 3 as function of the tank slenderness parameter $\gamma=H / R$.

The total impulsive base moment immediately below the tank bottom is given as

$$
M_{i}^{*}=m_{i} h_{i}^{*} A_{\lg }(t),
$$

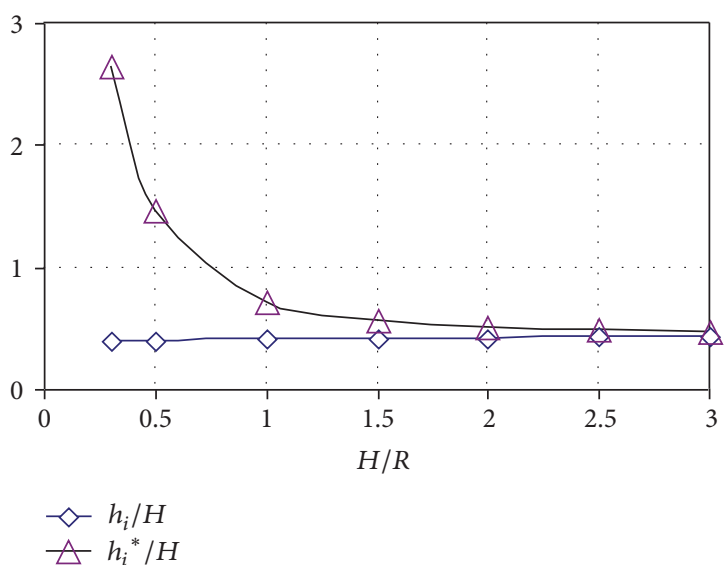

Figure 4: Ratios $h_{i} / H$ and $h_{i}{ }^{*} / H$ as functions of the parameter tank slenderness.

where

$$
\begin{aligned}
h_{i}^{*}= & H \\
& \cdot \frac{1 / 2+2 \gamma \sum_{n=0}^{\infty}\left(\left(v_{n}+2(-1)^{n+1} I_{1}\left(\nu_{n} / \gamma\right)\right) / v_{n}^{4} I_{1}^{\prime}\left(\nu_{n} / \gamma\right)\right)}{2 \gamma \sum_{n=0}^{\infty}\left(I_{1}\left(v_{n} / \gamma\right) / \nu_{n}^{3} I_{1}^{\prime}\left(v_{n} / \gamma\right)\right)},
\end{aligned}
$$

and total impulsive base moment immediately above the tank bottom is

$$
M_{i}=m_{i} h_{i} A_{g}(t),
$$

where

$$
\begin{aligned}
h_{i}= & H \\
& \cdot \frac{\sum_{n=0}^{\infty}\left((-1)^{n} I_{1}\left(\nu_{n} / \gamma\right) / \nu_{n}^{4} I_{1}^{\prime}\left(\nu_{n} / \gamma\right)\right)\left(\nu_{n}(-1)^{n}-1\right)}{\sum_{n=0}^{\infty}\left(I_{1}\left(\nu_{n} / \gamma\right) / \nu_{n}^{3} I_{1}^{\prime}\left(\nu_{n} / \gamma\right)\right)} .
\end{aligned}
$$

The quantities $h_{i}$ and $h_{i}{ }^{*}$ are plotted in Figure 4 as function of the tank slenderness parameter $\gamma=H / R$.

2.2. Convective Component. The spatial-temporal variation of the "convective" (sloshing) pressure component is given by the expression

$$
\begin{aligned}
p_{c} & (\xi, \zeta, \theta, t) \\
& =\rho \sum_{n=1}^{\infty} \psi_{n} \cos \left(\nu_{n} \gamma \zeta\right) J_{1}\left(\nu_{n} \xi\right) \cos \theta A_{c n}(t),
\end{aligned}
$$

where

$$
\psi_{n}=\frac{2 R}{\left(\lambda_{n}^{2}-1\right) J_{1}\left(\lambda_{n}\right) \cosh \left(\lambda_{n} \gamma\right)},
$$

$J_{1}$ is Bessel function of the first order, and $\lambda_{n}$ are the roots of the first-order Bessel function of the first kind $\left(\lambda_{1}=1.8412\right.$; $\lambda_{2}=5.3314 ; \lambda_{3}=8.5363, \lambda_{4}=11.71, \lambda_{5}=14.66$, and $\lambda_{5+i}=$ $\left.\lambda_{5}+5 i(i=1,2, \ldots)\right) \cdot A_{c n}(t)$ is acceleration time-history of the response of a single-degree-of-freedom oscillator having a circular frequency $\omega_{c n}$ given by

$$
\omega_{c n}=\sqrt{\frac{g \lambda_{n} \tanh \left(\lambda_{n} \gamma\right)}{R}},
$$




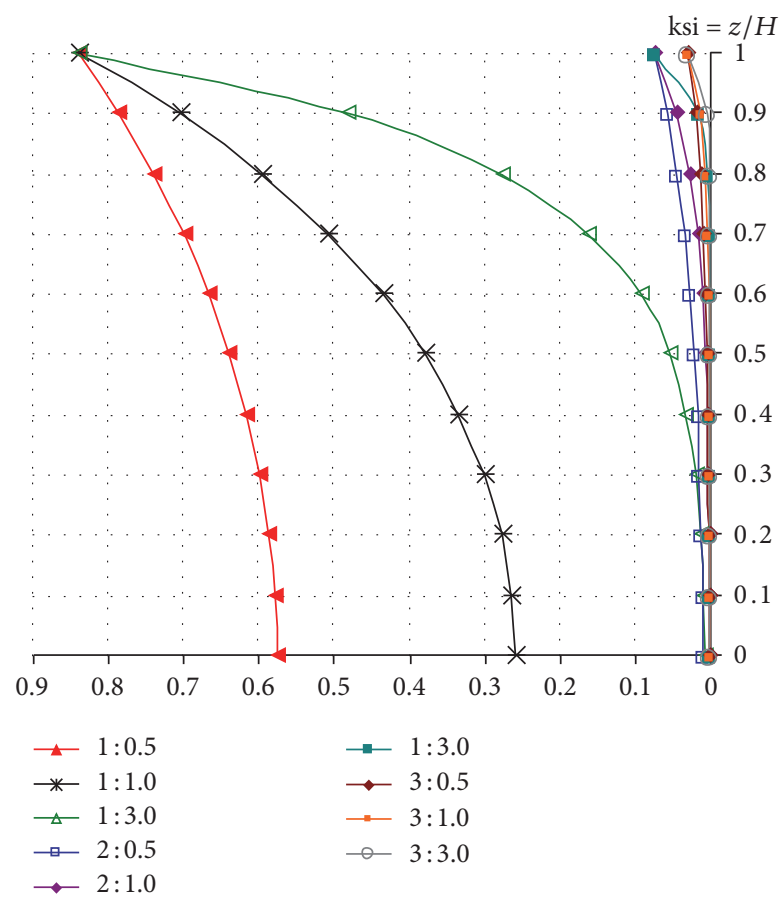

FIGURE 5: Variation of convective pressures along the height for values of the tank slenderness parameter $\gamma=H / R: 0.5,1.0$, and 3.0.

so

$$
T_{c n}=\frac{2 \pi}{\sqrt{g \lambda_{n} \tanh \left(\lambda_{n} \gamma\right) / R}}
$$

and damping ratio appropriate for the sloshing of the fluid.

Only the first oscillating, or sloshing, mode and frequency of the oscillating liquid $(n=1)$ need to be considered in expression for design purposes

$$
\omega_{c 1}=\frac{4.2}{\sqrt{R}},
$$

in which the oscillation yields periods of the order for the usual values of $R$ are few seconds.

Figure 5 shows the functions of sloshing pressure distributions along the height of tank for the tank slenderness parameters $\gamma=H / R: 0.5,1.0$, and 3.0, the first three modes.

The horizontal resultants of the convective pressure are the total base shear and the total convective moments. The total convective base shear is given as

$$
Q_{c}(t)=\sum_{n=1}^{\infty} m_{c n} A_{c n}(t),
$$

where

$$
m_{c n}=m \frac{2 \tanh \left(\lambda_{n} \gamma\right)}{\lambda_{n} \gamma\left(\lambda_{n}^{2}-1\right)} .
$$

$m_{c n}$ is the $n$th modal convective mass and $h_{c n}$ is its height; see Figure 10.

$$
h_{c n}=H\left(1+\frac{1-\cosh \left(\lambda_{n} \gamma\right)}{\lambda_{n} \gamma \sin \left(\lambda_{n} \gamma\right)}\right) .
$$

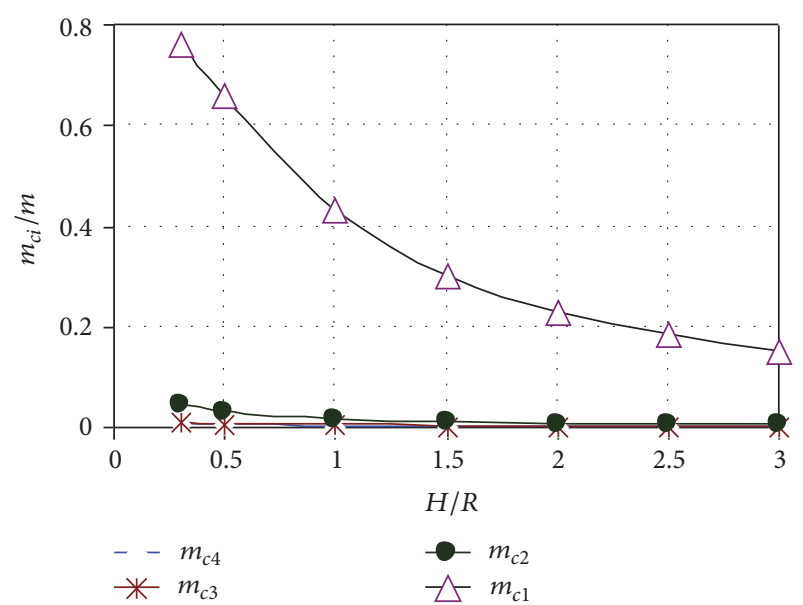

FIGURE 6: Ratios $m_{c i} / m$ as function of the tank slenderness parameter for $i=1,2,3$, and 4 .

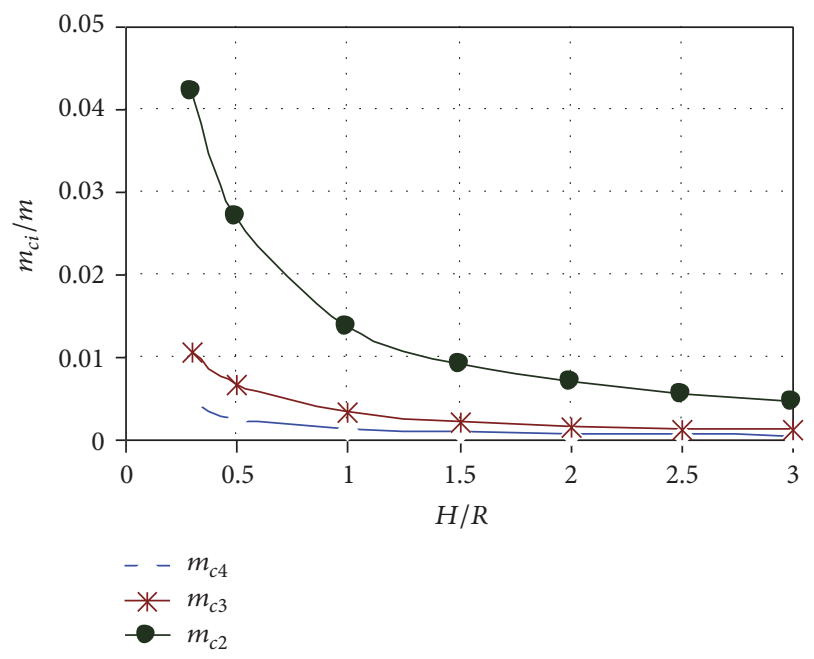

FIgURE 7: Ratios $m_{c i} / m$ as function of the tank slenderness parameter for $i=2,3$, and 4 .

Figures 6 and 7 show the quantities $m_{c i}$ as function of the tank slenderness parameter $\gamma=H / R$ :

(i) for $i=1,2,3$, and 4 in Figure 6

(ii) only for $i=2,3$, and 4 in Figure 7.

The total convective (overturning) moment immediately below the bottom plate of the tank is

$$
M_{c}^{*}(t)=\sum_{n=1}^{\infty}\left(m_{c n} A_{c n}(t)\right) h_{c n}^{*}=\sum_{n=1}^{\infty} Q_{c n}(t) h_{c n}^{*},
$$

where

$$
h_{c n}^{*}=H\left(1+\frac{2-\cosh \left(\lambda_{n} \gamma\right)}{\lambda_{n} \gamma \sin \left(\lambda_{n} \gamma\right)}\right) .
$$

The total convective (bending) moment in tank wall immediately above the bottom plate is

$$
M_{c}(t)=\sum_{n=1}^{\infty}\left(m_{c n} A_{c n}(t)\right) h_{c n}=\sum_{n=1}^{\infty} Q_{c n}(t) h_{c n},
$$




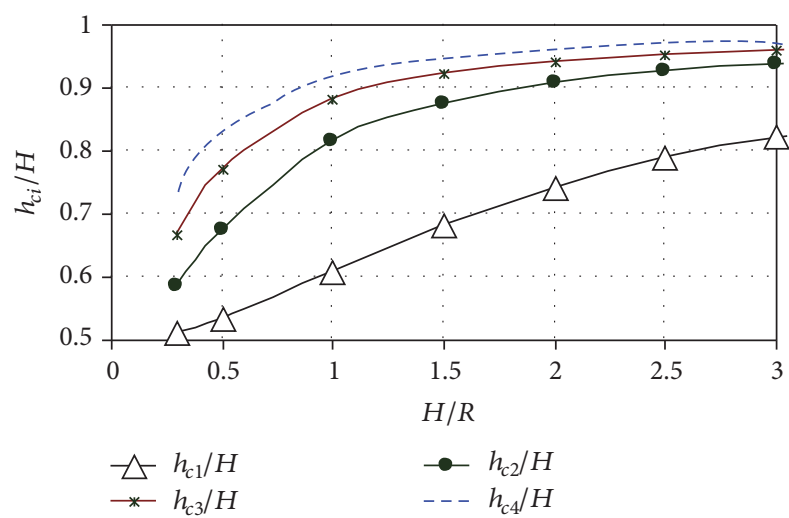

FIGURE 8: Ratios $h_{c i} / H$ as functions of the tank slenderness parameter.

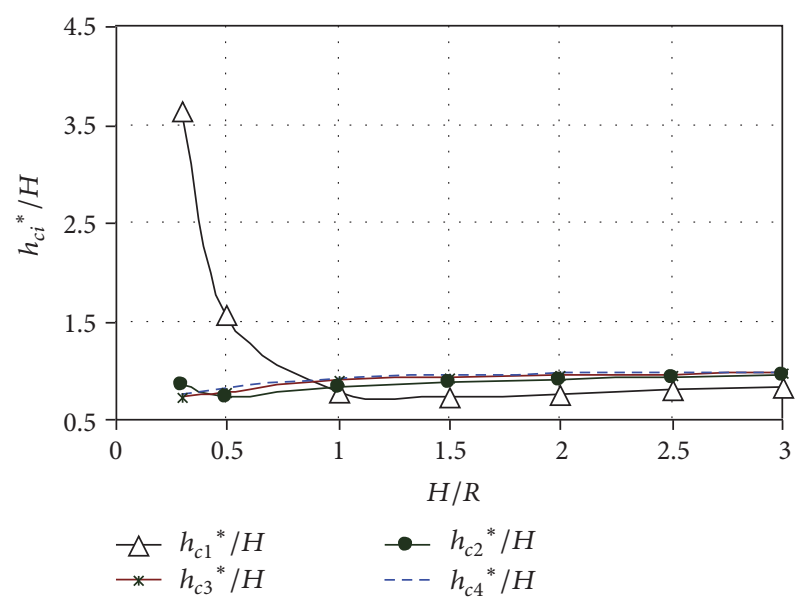

FIGURE 9: Ratios $h_{c i}{ }^{*} / H$ as functions of the tank slenderness parameter.

where

$$
h_{c n}=H\left(1+\frac{1-\cosh \left(\lambda_{n} \gamma\right)}{\lambda_{n} \gamma \sin \left(\lambda_{n} \gamma\right)}\right)
$$

The quantities $h_{c i}$ and $h_{c i}{ }^{*}$ as function of the tank slenderness parameter $\gamma=H / R$ are seen in Figures 8 and 9, the quantities $h_{c i}$ in Figure 8 and the quantities $h_{c i}{ }^{*}$ in Figure 9.

The convective component of the response may be obtained from that of oscillators having masses $m_{c n}$, attached to the rigid tank through springs having stiffness $k_{n}=\omega_{n}^{2} m_{c n}$. The tank is subjected to the ground acceleration time-history $A_{g}(t)$ and the masses responds with accelerations $A_{c n}(t) . h_{c n}^{*}$ or $h_{c n}$ is the level where the oscillator needs to be applied in order to give the correct value of $M_{c n}^{*}$ or $M_{c n}$, respectively.

2.3. Mechanical Model. The dynamic analysis of a liquidfilled tank may be carried out using the concept of generalized single-degree-of-freedom (SDOF) systems representing the impulsive and convective modes of vibration of the tankliquid system as shown in Figure 10. For practical applications, only the first convective mode of vibration needs to be considered in the analysis of mechanical model.

\section{Numerical Example and Results}

In this study fluid filling of ground-supported cylindrical rigid tank is analyzed. The characteristics of fluid filling are $H=2 \mathrm{~m}$ and $R$, inner radiuses of cylindrical tanks, where $R$ depended on tank slenderness parameter $\gamma=H / R$.

For the tank slenderness parameter $\gamma=0.3$ is the inner radius of $\operatorname{tank} R 6.667 \mathrm{~m}$,

(i) for $\gamma=0.5 \Rightarrow R$ is $4 \mathrm{~m}$,

(ii) for $\gamma=0.7 \Rightarrow R=2.857 \mathrm{~m}$,

(iii) for $\gamma=1 \Rightarrow R=2 \mathrm{~m}$,

(iv) for $\gamma=2 \Rightarrow R=1 \mathrm{~m}$,

(v) for $\gamma=3, R$ is given $0.667 \mathrm{~m}$.

The material characteristic of fluid filling $\left(\mathrm{H}_{2} \mathrm{O}\right)$ is density $\rho_{w}=1,000 \mathrm{~kg} / \mathrm{m}^{3}$. As the excitation input we consider horizontal earthquake load given by the accelerogram of the earthquake in Loma Prieta, California (18.10.1989), Figure 11.

The elastic response spectra for the Loma Prieta accelerogram in California were used for calculation of seismic response in the given examples, cylindrical fluid filling. The elastic response spectra drawn for damping $0.5 \%, 2 \%$, $4 \%, 5 \%, 7 \%$ can be seen in Figure 12 . The impulsive spectral accelerations are obtained from a 5\% damped elastic response spectrum and the convective spectral accelerations are obtained from a $0.5 \%$ damped elastic response spectrum.

The peak values of accelerated fluid pressure onto wall are located at the bottom of the container wall and presented in Figure 13 as functions of the tank slenderness parameter $\gamma$. The peak values of pressures of accelerated fluid at the bottom of the tanks wall are bigger in short and large-scale tanks compared with pressures in narrow and high (slender) tanks.

The fluid pressure is zero pressure at the original position of the free surface of the fluid in the static situation. The peak values of accelerated fluid pressure onto wall at the original position of the free surface are shown in Figure 14 as function of the tank slenderness parameter.

Figures 15 and 16 show

(i) comparison of the total mass $m$ in $[\mathrm{kg}]$ of the fluid contained in tank as function of the tank slenderness parameter $\gamma$,

(ii) comparison of component ratio of impulsive and convective fluid masses contained in tank as functions of the tank slenderness parameter $\gamma$. If the tank slenderness parameter $\gamma$ is smaller, then the component of convective fluid mass is bigger and the component of impulsive fluid mass is smaller.

Dependence of $h_{i}, h_{c}$, and $h_{i}{ }^{*}$ on the tank slenderness parameter is seen in Figure 17; they correlate well with $h_{i}, h_{c}$, and $h_{i}{ }^{*}$ in Figures 4, 5, and 7.

Figure 18 documents comparison of the total base shear $V$ in $[\mathrm{kN}]$ of the fluid contained in tank as function of the tank slenderness parameter $\gamma$. Figure 19 shows comparison of component ratio of impulsive and convective component of base shear $V$ on tank as functions of the tank slenderness 


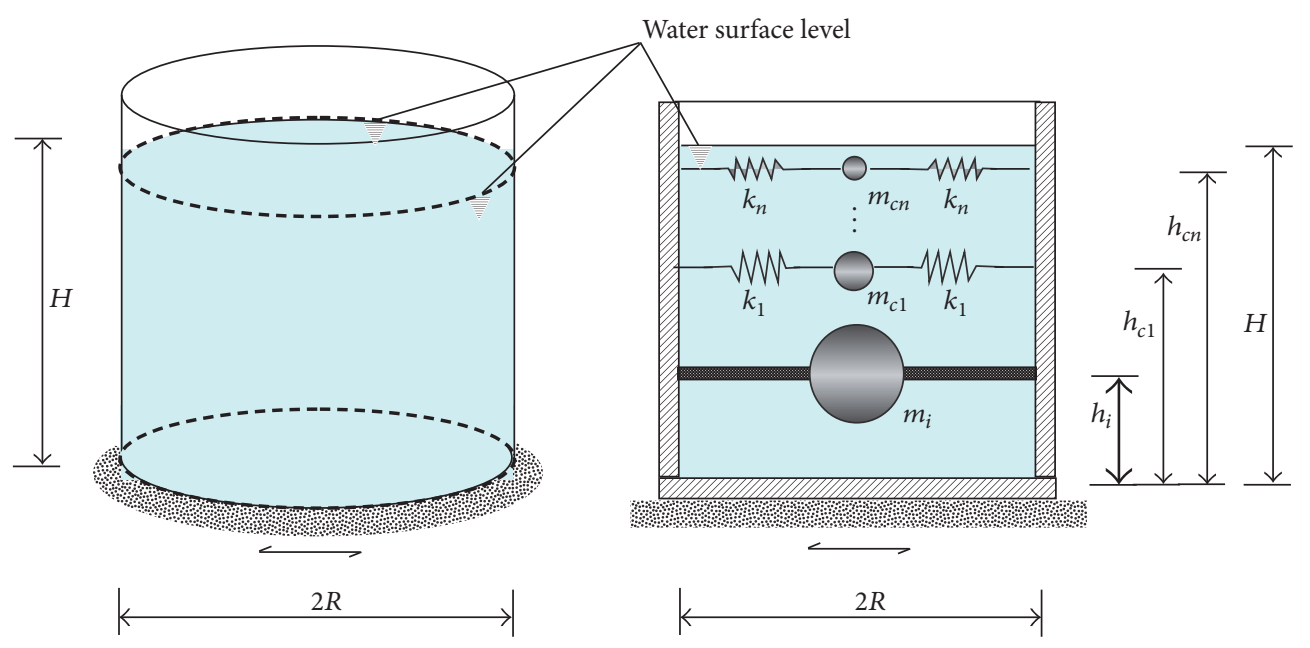

FIGURE 10: Liquid-filled tank modeled by generalized single-degree-of-freedom systems.

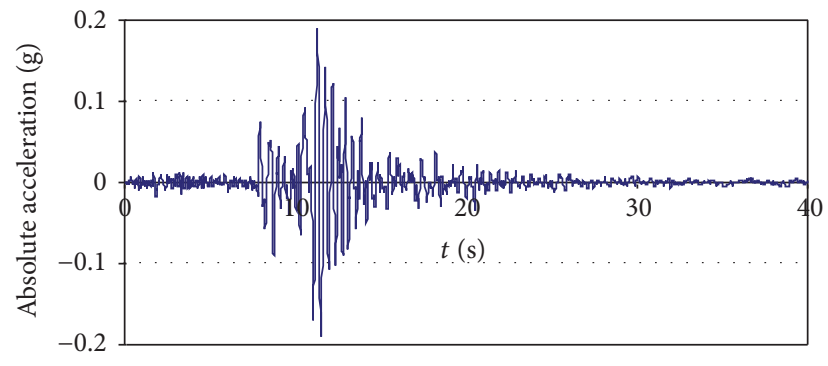

Figure 11: Accelerogram of Loma Prieta, California.

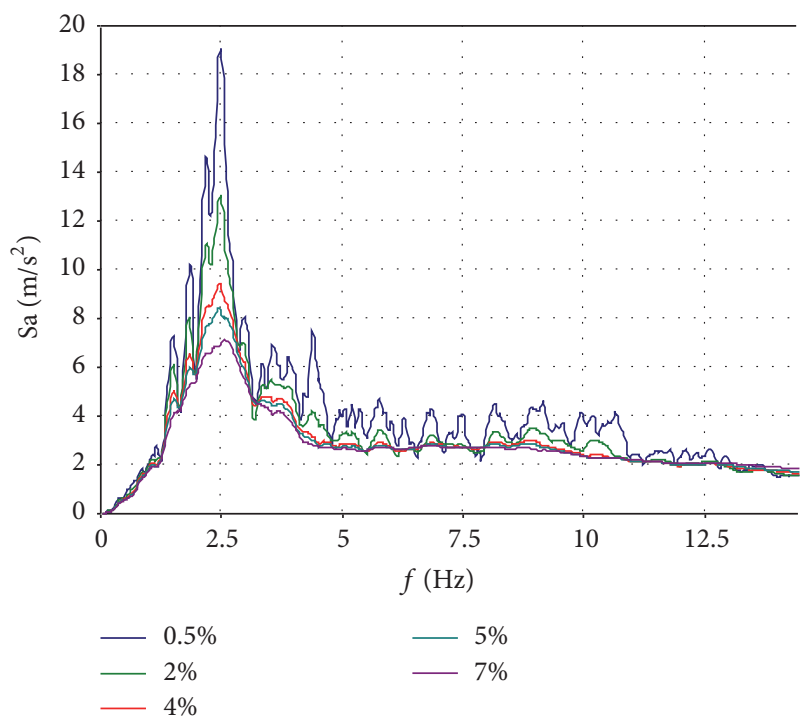

Figure 12: The response spectra for the Loma Prieta accelerogram from Figure 11.

parameter. If the tank slenderness is smaller, then the component of convective base shear is bigger and the component of impulsive base shear is smaller.

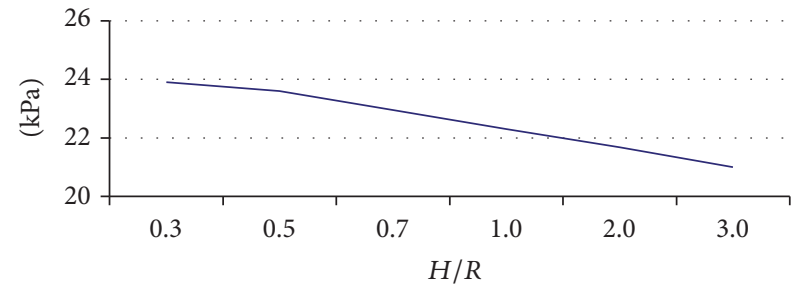

FIGURE 13: The peak value of fluid pressure in $[\mathrm{kPa}]$ on the bottom of tank wall as functions of the tank slenderness $\gamma$.

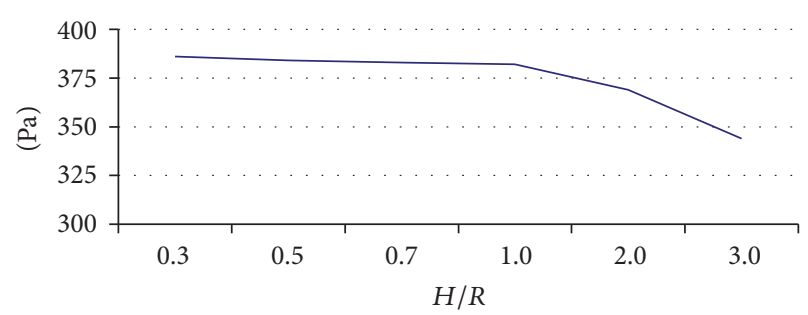

FIGURE 14: The peak value of fluid pressure in $[\mathrm{kPa}]$ on the tank wall at the original position of the fluid free surface as function of the tank slenderness parameter $\gamma$.

Figure 20 shows comparison of the total bending moments $M$ and overturning moments $M^{*}$ in $[\mathrm{kNm}]$ of the fluid contained in tank as functions of the tank slenderness parameter $\gamma$.

Comparison of component ratio of impulsive and convective fluid moments in tank as functions of the tank slenderness parameter $\gamma$ can be seen in Figures 21 and 22 . Figure 21 shows comparison of total the bending moments $M$ and Figure 22 describes comparison of total overturning moments $M^{*}$. If the tank slenderness is smaller, then the components of convective fluid moments are bigger and the components of impulsive fluid moments are smaller. 


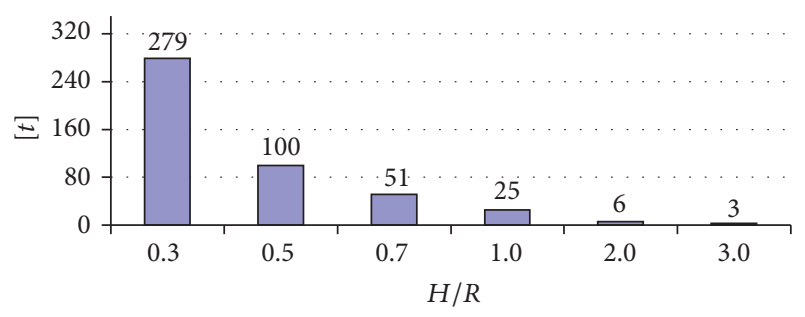

FIGURE 15: Comparison of the total mass of the fluid contained in tank as function of the tank slenderness parameter $\gamma$.

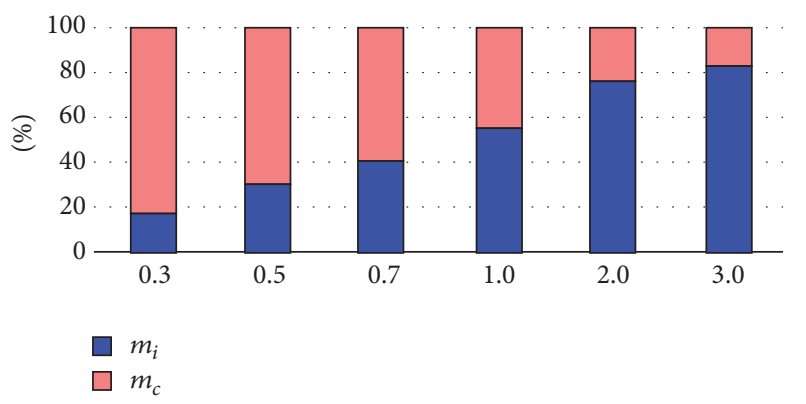

FIGURE 16: Comparison of the total mass components (impulsive and convective) of the fluid contained in tank as functions of the tank slenderness parameter $\gamma$.

\section{Conclusions}

The seismic analysis of liquid storage containers is highly complex problem. Therefore, the knowledge of earthquake fluid effect on solid domain of tanks and appropriate modeling of the liquid storage tanks is essential for dynamic analysis and seismic response evaluation of earthquake resistance structure/facility, tanks. The dynamic behavior for liquidcontaining structures has to use different approach as for solid structure. The weight of storage liquid varies in time because of variable liquid storage level; accordingly there exists sloshing of fluid which influences the response of the tank. The thoroughgoing dynamic analysis of contained liquid is necessary. The knowledge of forces acting onto containers, pressures in solid of tanks, surface sloshing process, and maximal height of liquids wave during an earthquake plays essential role in reliable and durable design of earthquake resistance containers. The analysis of a coupled multiphysics system is frequently required nowadays, to understand the behavior of the system. The motion of contained fluid in tanks may by expressed as the sum of two separate contributions, impulsive and convective actions. The mechanical model represents the dynamic analysis of fluid-filled tank, using the concept of generalized SDOF systems, representing the impulsive and convective (sloshing) modes of vibration. This paper summarizes the results of a comprehensive analytical investigation concerning the seismic analysis of groundsupported cylindrical tank-fluid filling effects on the tanks, subject to a horizontal component of earthquake ground motion. The tanks were excited by acceleration of Loma Prieta earthquake in California. Basic responses of the interest

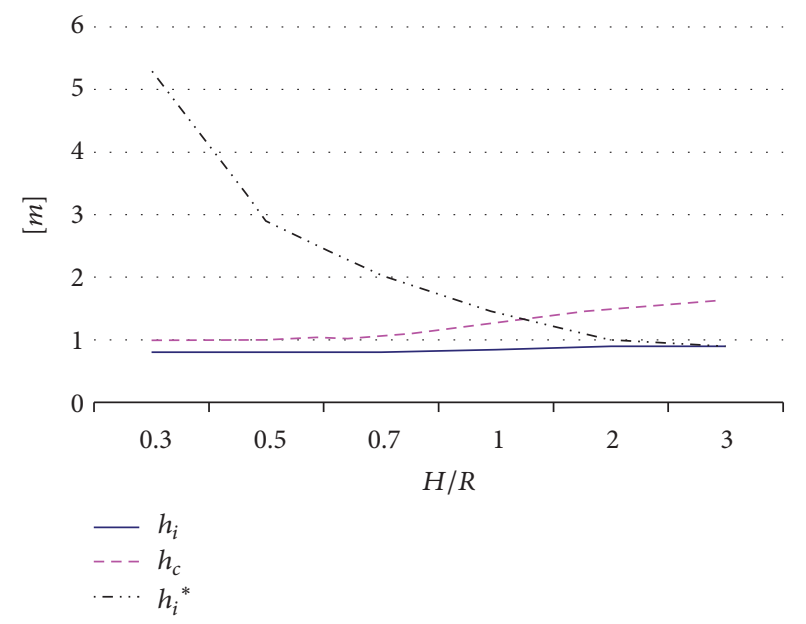

Figure 17: Comparison of $h_{i}, h_{c}$, and $h_{i}{ }^{*}$ as functions of the tank slenderness parameter $\gamma$.

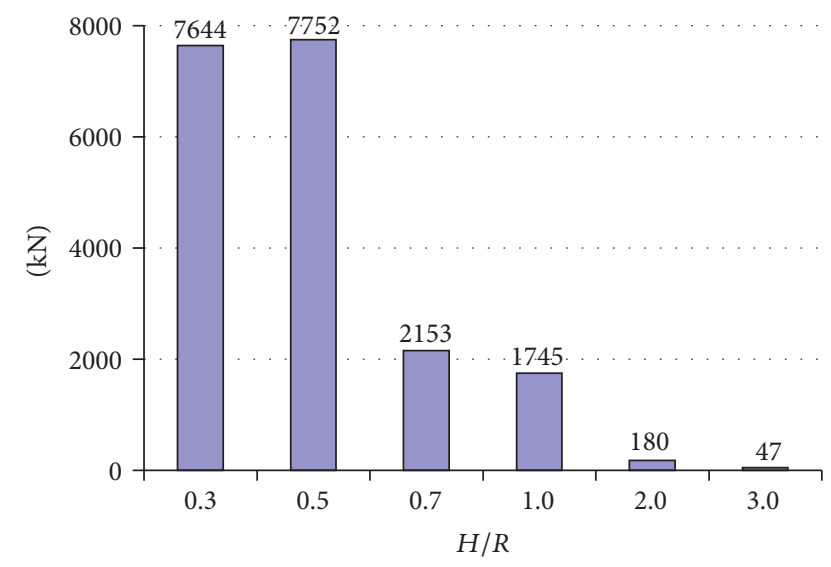

FIGURE 18: Comparison of the total base shear as function of the tank slenderness parameter $\gamma$.

were the peak values of fluid pressures, the total base shear, the total bending, and the overturning moments of fluid as functions of the tank slenderness parameter and their ratios of impulsive and convective effects. In this study fluid filling of ground-supported cylindrical rigid tank is analyzed. The geometrical characteristics of fluid filling $\left(\mathrm{H}_{2} \mathrm{O}\right.$, density $\rho_{w}=1,000 \mathrm{~kg} / \mathrm{m}^{3}$ ) for $H=2 \mathrm{~m}$, where $R$ represents the inner radiuses of cylindrical tanks depended on tank slenderness parameter $\gamma=H / R$. Inner container radiuses are given as $6.667 \mathrm{~m}, 4 \mathrm{~m}, 2.857 \mathrm{~m}, 2 \mathrm{~m}, 1 \mathrm{~m}$, and $0.667 \mathrm{~m}$ of fluid filling.

It is seen from results in Section 3 that

(i) the hydrodynamic pressures are bigger in short and large-scale tanks (tanks with smaller tank slenderness parameter) than in narrow high (slender) tanks;

(ii) the impulsive components of hydrodynamic pressures give maximum values on the bottom of tank wall and they obtain bigger values in narrow high (slender) tanks; 


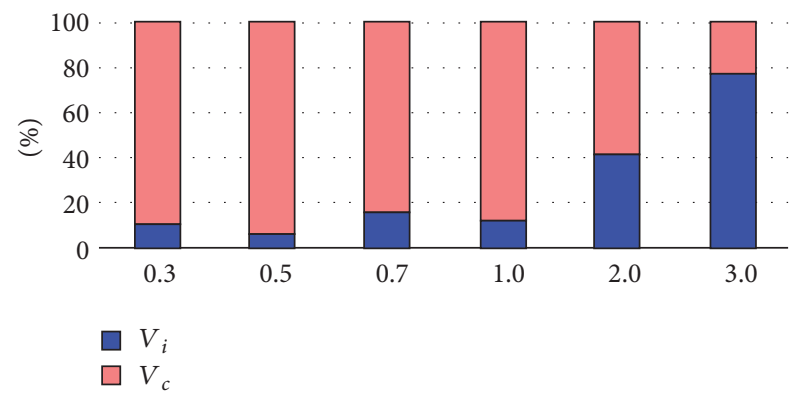

FIGURE 19: Comparison of the base shear components (impulsive and convective) as functions of the tank slenderness parameter $\gamma$.

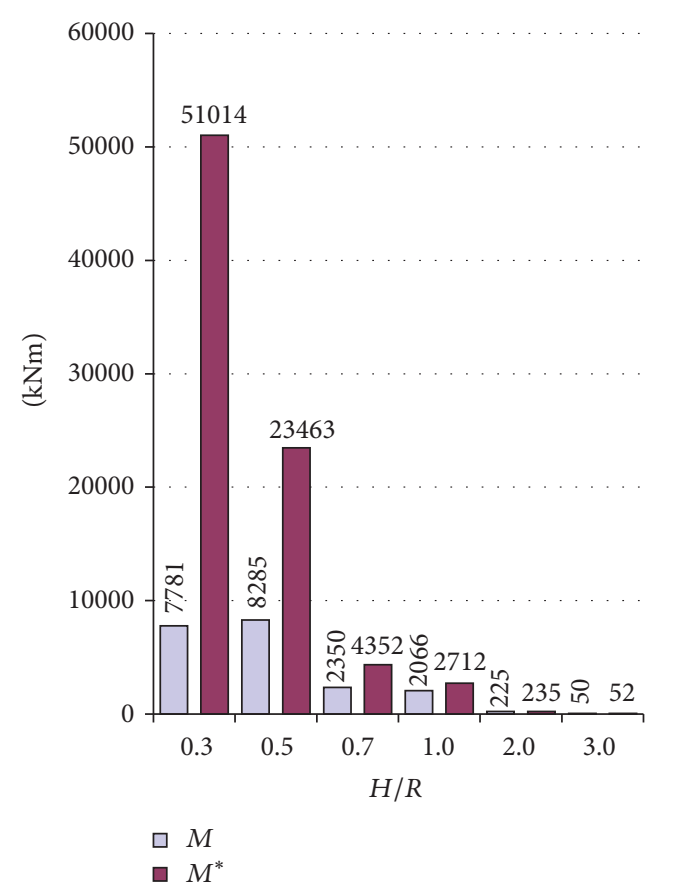

FIgURE 20: Comparison of the total bending moments as functions of the tank slenderness parameter $\gamma$.

(iii) the convective components of hydrodynamic pressures receive the maximum values on the tank wall at the original position of the fluid free surface and they are bigger in short and large-scale tanks than in narrow high (slender) tanks;

(iv) the total mass of fluid, the total base shear, and the total moments are bigger in narrow slender tanks; these results are due to bigger volume of contained liquid;

(v) the impulsive component of fluid masses obtains bigger values in narrow and slender tanks;

(vi) the bigger values of the convective fluid masses are in short and large-scale tanks;

(vii) the impulsive component of base shear receives bigger values in narrow slender tanks and on the other sides

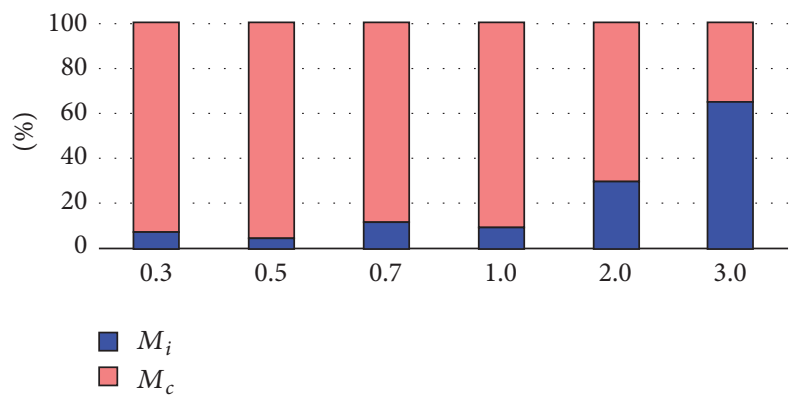

FIGURE 21: Comparison of bending moment components (impulsive and convective) as functions of the tank slenderness parameter $\gamma$.

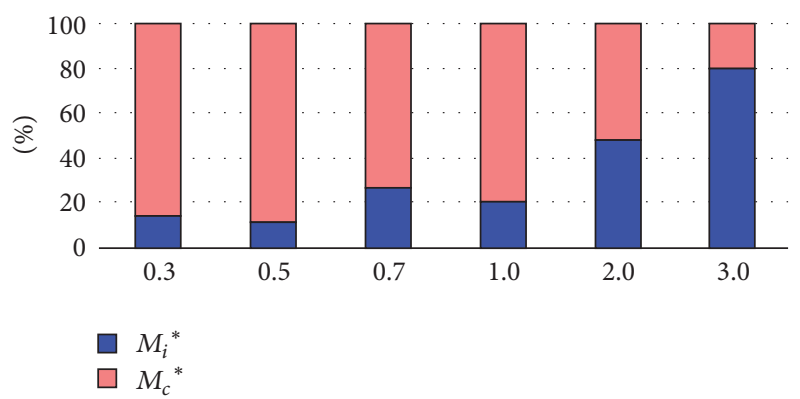

FIGURE 22: Comparison of overturning moment components (impulsive and convective) total base shear as functions of the tank slenderness parameter $\gamma$.

the convective fluid base shear is bigger in short and large-scale tanks;

(viii) the bigger values of fluid impulsive bending and overturning moments are given in narrow and slender tanks;

(ix) the convective components of moments (bending and overturning) give the bigger values in short and largescale tanks.

The knowledge of fluid effect on solid domain of tanks and their interdependence is, due to earthquake, significant for safe and economic design of earthquake-resistant structure/facility, containers.

\section{Competing Interests}

The authors declare that they have no conflict of interests.

\section{Acknowledgments}

This work was supported by the Scientific Grant Agency of the Ministry of Education of Slovak Republic and the Slovak Academy of Sciences under Project VEGA 1/0477/15.

\section{References}

[1] A. Di Carluccio, G. Manfredi, I. Iervolino, and G. Fabbrocino, "Fragility analysis of liquid storage steel tanks in seismic areas," 
in Proceedings of the 4th International Structural Engineering and Construction Conference, ISEC-4-Innovations in Structural Engineering and Construction, pp. 1049-1055, CRC Press, Melbourne, Australia, September 2007.

[2] S. Dorafshan, F. Behnamfar, A. Khamesipour, and M. Motosaka, "Condensed hyperelements method of non-vertical consistent boundaries for wave propagation analysis in irregular media," Earthquake Engineering and Engineering Vibration, vol. 12, no. 4, pp. 547-559, 2013.

[3] G. Fabbrocino, I. Iervolino, F. Orlando, and E. Salzano, "Quantitative risk analysis of oil storage facilities in seismic areas," Journal of Hazardous Materials, vol. 123, no. 1-3, pp. 61-69, 2005.

[4] N. Jendželovský and L. Baláž, "Numerical modeling of cylindrical tank and compare with experiment," Applied Mechanics and Materials, vol. 617, pp. 148-151, 2014.

[5] K. Kotrasova and E. Kormanikova, "Seismic response of waste storage," MATEC Web of Conference, vol. 76, Article ID 02004, 6 pages, 2016.

[6] M. Krejsa, P. Janas, and V. Krejsa, "Software application of the DOProC method," International Journal of Mathematics and Computers in Simulation, vol. 8, no. 1, pp. 121-126, 2014.

[7] S. Mönkölä, "On the accuracy and efficiency of transient spectral element models for seismic wave problems," Advances in Mathematical Physics, vol. 2016, Article ID 9431583, 15 pages, 2016.

[8] G. W. Housner, Dynamic Pressures on Accelerated Fluid Containers, Division of Engineering, California Institute of Technology, Pasadena, Calif, USA, 1955.

[9] P. K. Malhotra, T. Wenk, and M. Wieland, "Simple procedure for seismic analysis of liquid-storage tanks," Structural Engineering International: Journal of the International Association for Bridge and Structural Engineering (IABSE), vol. 10, no. 3, pp. 197-201, 2000.

[10] J. Michel and M. Mihalikova, "Degradation of pipes properties in creep conditions," Acta Metallurgica Slovaca, vol. 2, pp. 108115, 2000.

[11] M. Žmindák and I. Grajciar, "Simulation of the aquaplane problem," Computers and Structures, vol. 64, no. 5-6, pp. 11551164, 1997.

[12] A. Doğangün and R. Livaoğlu, "A comparative study of the seismic analysis of rectangular tanks according to different codes," in Proceedings of the 14th World Conference on Earthquake Engineering, Beijing, China, October 2008.

[13] S. H. Helou, "Seismic induced forces on rigid water storage tanks," Asian Journal of Engineering and Technology, vol. 2, no. 4, pp. 310-315, 2014.

[14] O. R. Jaiswal, D. C. Rai, and S. K. Jain, "Review of seismic codes on liquid-containing tanks," Earthquake Spectra, vol. 23, no. 1, pp. 239-260, 2007.

[15] European Committee for Standardisation, "Eurocode 8: design of structures for earthquake resistance-part 4: silos, tanks and pipelines," EN 1998-4, 2006.

[16] IITK, IITK-GSDMA Guidelines for Seismic Design of Liquid Storage Tanks-Provisions with Commentary and Explanatory Examples, Indian Institute of Technology Kanpur, Kanpur, India, 2005.

[17] J. Králik and J. Králik Jr., "Probability assessment of analysis of high-rise buildings seismic resistance," Advanced Materials Research, vol. 712-715, pp. 929-936, 2013. 


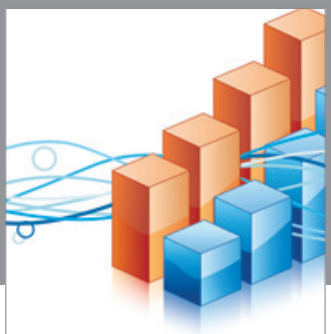

Advances in

Operations Research

vatem alat4

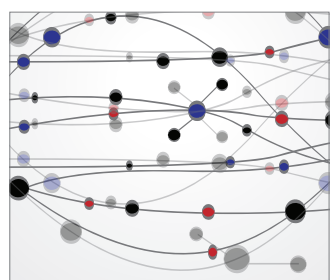

\section{The Scientific} World Journal
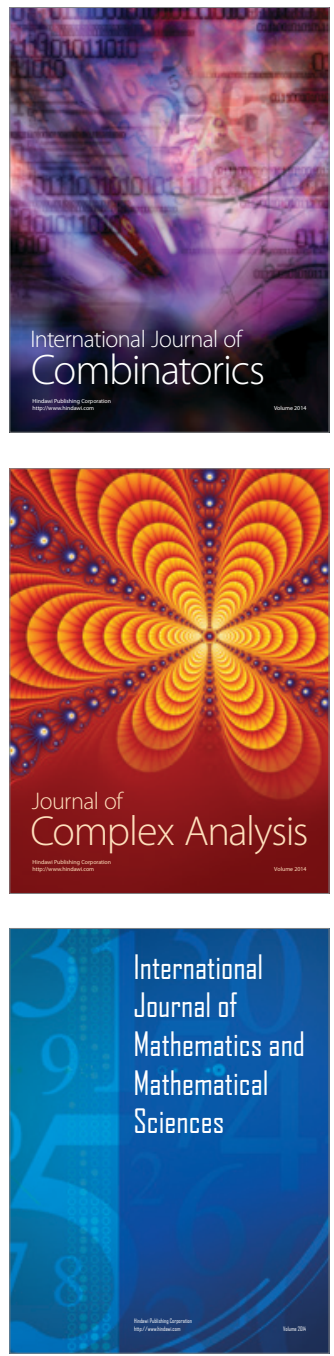
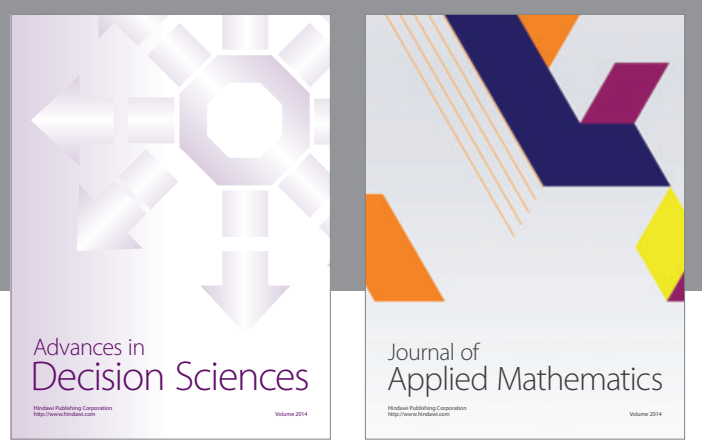

Algebra

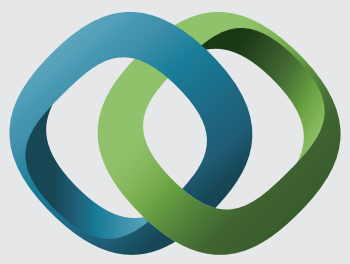

\section{Hindawi}

Submit your manuscripts at

https://www.hindawi.com
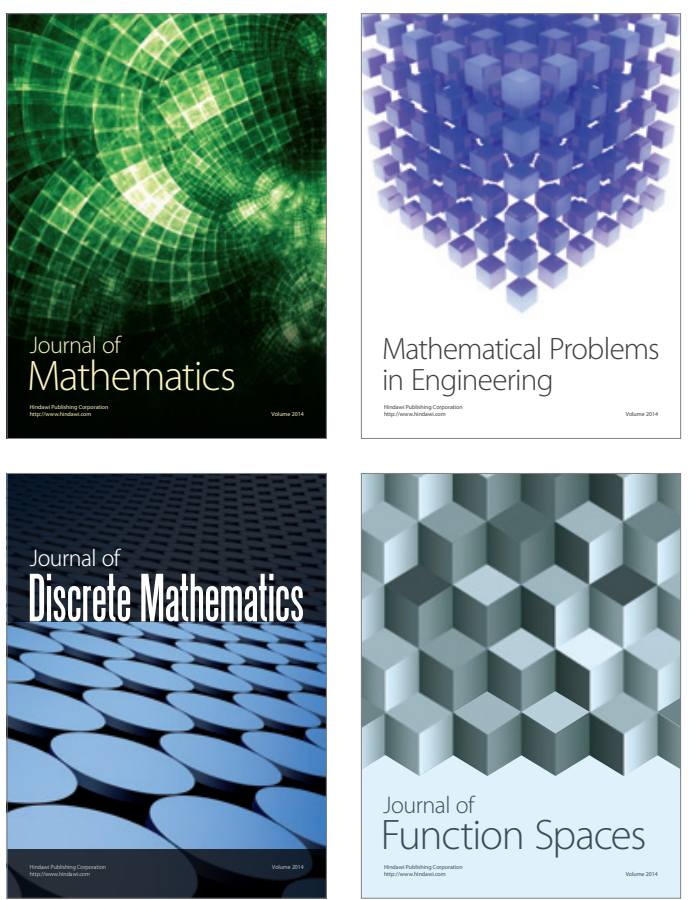

Mathematical Problems in Engineering
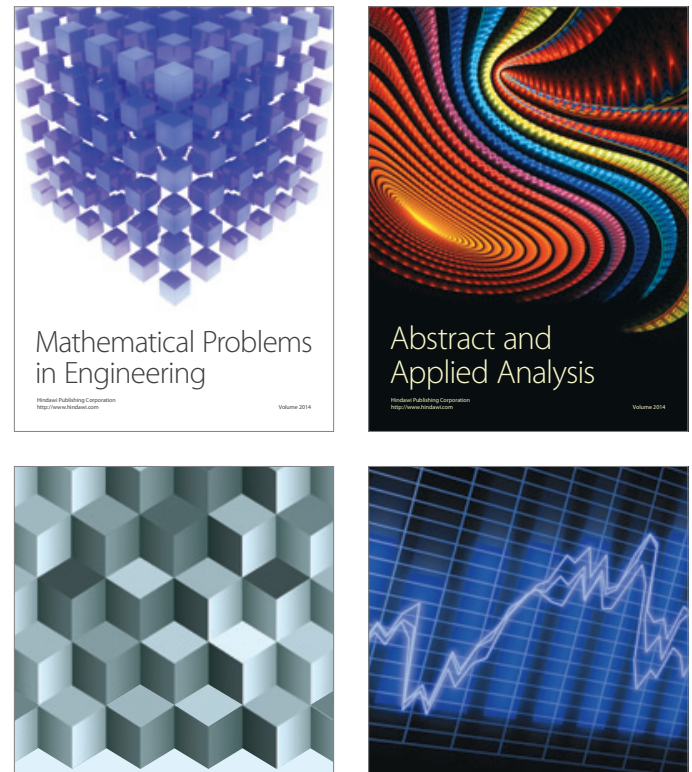

Journal of

Function Spaces

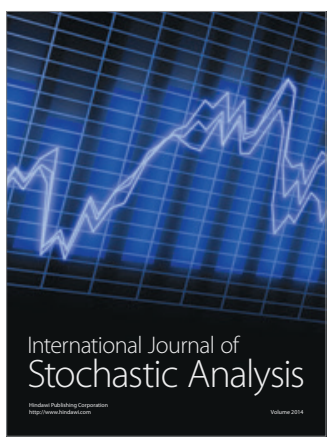

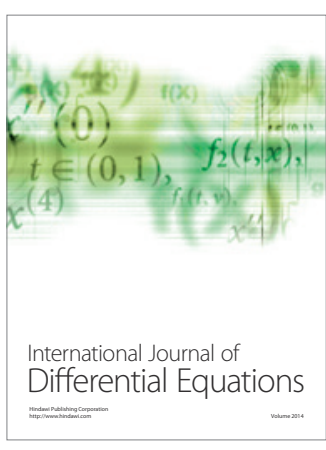
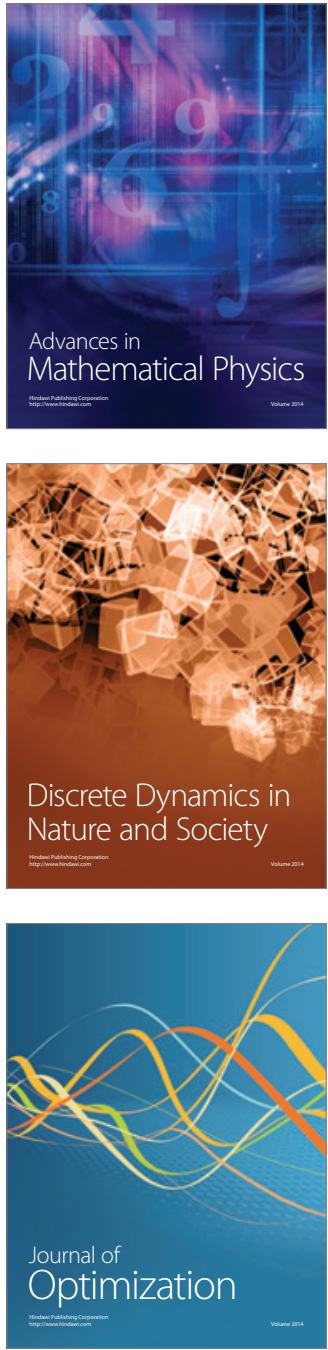